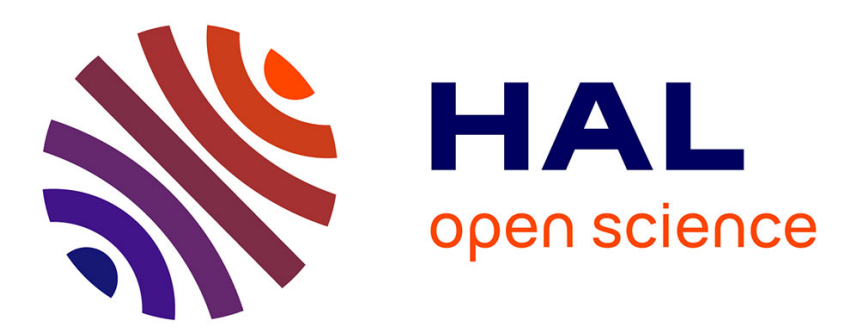

\title{
Femtosecond and coherent effects in bulk CdSe and CdSexS 1-x doped glasses
}

\author{
N. Peyghambarian, S.W. Koch
}

\section{To cite this version:}

N. Peyghambarian, S.W. Koch. Femtosecond and coherent effects in bulk CdSe and CdSexS 1-x doped glasses. Revue de Physique Appliquée, 1987, 22 (12), pp.1711-1715. 10.1051/rphysap:0198700220120171100 . jpa-00245731

\section{HAL Id: jpa-00245731 https://hal.science/jpa-00245731}

Submitted on 1 Jan 1987

HAL is a multi-disciplinary open access archive for the deposit and dissemination of scientific research documents, whether they are published or not. The documents may come from teaching and research institutions in France or abroad, or from public or private research centers.
L'archive ouverte pluridisciplinaire HAL, est destinée au dépôt et à la diffusion de documents scientifiques de niveau recherche, publiés ou non, émanant des établissements d'enseignement et de recherche français ou étrangers, des laboratoires publics ou privés. 


\title{
Femtosecond and coherent effects in bulk CdSe and $\mathrm{CdSe}_{x} \mathrm{~S}_{1-x}$ doped glasses
}

\author{
N. Peyghambarian and S. W. Koch \\ Optical Sciences Center, University of Arizona, Tucson, AZ 85721, U.S.A.
}

(Reçu le 25 juin 1987, accepté le 31 août 1987)

\begin{abstract}
Résumé. - Le CdSe solide et les microcristaux de $\mathrm{CdSe}_{x} \mathrm{~S}_{1-x}$ en matrice vitreuse sont étudiés au moyen de techniques laser femtosecondes. La dynamique ultrarapide des porteurs photo-générés est mesurée. La saturation locale spectrale due à la création d'une population de porteurs non thermalisée est observée dans les deux types de matériau. La durée de vie de recombinaison des porteurs est mesurée. L'interaction cohérente entre l'impulsion sonde et la polarisation induite dans le milieu due à l'excitation bande à bande par l'impulsion pompe est observée. Cet effet cohérent se manifeste sous forme d'oscillations dans le spectre de fréquence pour les temps du début quand la sonde précède la pompe. Une théorie semi-classique est développée pour analyser le comportement observé. Elle permet de calculer le spectre de transmission d'une impulsion sonde faible qui interagit avec la polarisation du milieu induite par la pompe. Un accord qualitatif entre la théorie et l'expérience est obtenu.
\end{abstract}

\begin{abstract}
Bulk CdSe and microcrystallites of $\mathrm{CdSe}_{x} \mathrm{~S}_{1-x}$ embedded in a glass matrix are studied using femtosecond laser techniques. The ultrafast dynamics of the photogenerated carriers are measured. Spectral hole burning due to creation of a non-thermal carrier population is observed in both types of materials. The carrier recombination lifetime is measured. Coherent interaction between the probe pulse and the polarization induced in the material as a result of band-to-band excitation by pump pulse is observed. This coherent effect manifests itself as oscillations in the frequency spectrum for very early times when the probe precedes the pump. A semiclassical theory is developed to analyse the observed behaviour. It calculates the transmission spectrum of a weak probe pulse which interacts with the pump-induced polarization of the medium. Qualitative agreement between theory and experiment is obtained.
\end{abstract}

Glasses doped with $\mathrm{CdSe}_{x} \mathrm{~S}_{1-x}$ microcrystallites have attracted much attention recently [1-15]. Semiconductor doped glasses are interesting for device applications and also for fundamental physics. Room-temperature capability, relatively large optical nonlinearity $\left(n_{2} \cong 10^{-8}-10^{-9} \mathrm{~cm}^{2} / \mathrm{kW}\right)$, wavelength tunability (obtained by changing the composition $x$ which changes the semiconductor bandedge), rapid response time ( $\cong 10 \mathrm{ps}$ ), ease and inexpensiveness of manufacture make these materials suitable for device application. The physics of quantum confinement effects in all three dimensions in semiconductor microcrystals makes these materials particularly attractive.

In order to observe quantum confinement effects, the crystallite sizes in the doped glasses have to be small in comparison to the relevant microscopic length scale (Bohr radius), and they should have a narrow size distribution. The microcrystallites in commercially available glasses have an average diameter of $\cong 150 \AA$ with a FWHM size distribution of $\cong 50 \AA$ [12]. Therefore, quantum confinement effects are usually not observable in commercial glasses [12]. However, a more uniform size distribution and small crystal diameters can be obtained through a careful heat treatment of the base glass. Soviet researchers have produced crystallites of $\mathrm{CdS}, \mathrm{CdSe}$ and $\mathrm{CuCl}$, as small at $12 \AA$ in diameter, with relatively uniform size distribution [13]. Also researchers at Corning have been able to make glasses with average crystallite diameters ranging from $30 \AA$ to $80 \AA$ with $24 \AA$ to $44 \AA$ FWHM size distribution, respectively [12]. Optical absorption, photoluminescence, X-ray diffraction and transmission electron microscopy have been used in order to examine the physical properties of the microcrystallites as a function of composition and development [12]. 
We have performed extensive experiments on commercially available doped glasses [6, 9, 10, 14], and for bulk CdSe for comparison. The origin of optical nonlinearity was investigated using nanosecond pump-probe techniques [10]. The magnitude of the nonlinear index of refraction was measured using both nonlinear interferometry and Kramers-Kronig transformation of absorption changes $[9,10]$. The carrier dynamics of the glasses and of bulk CdSe were investigated using our femtosecond laser.

The laser system consists of a colliding-pulse mode-locked dye laser capable of generating pulses of $\cong 35 \mathrm{fs}$ duration centred around $620 \mathrm{~nm}$. These pulses are amplified in a dye amplifier using a 10$\mathrm{kHz}$ copper-vapor laser. The amplification broadens the pulses to $120 \mathrm{fs}$ to $150 \mathrm{fs}$ pulse durations. A portion of the amplified pulses was used to generate a white light continuum probe pulse while the remainder was used as pump pulse. Induced changes in the samples probe transmission were measured over a $125 \mathrm{meV}$ portion of the spectrum centred about the pump-pulse energy of $2.0 \mathrm{eV}$. The pump and probe pulses are orthogonally polarized. The transmission difference between excited and unexcited samples divided by the transmission of the unexcited sample, $\left(T-T_{0}\right) / T_{0}$, i.e. differential transmission spectra (DTS), was measured as a function of time delay between the pump and probe pulses. Differential absorption spectra can be obtained from DTS.

Figure 1 shows differential transmission spectra for a $\mathrm{CdSe}_{0.8} \mathrm{~S}_{0.2}$ glass at $300 \mathrm{~K}$ for various time delays between the pump and probe pulses. Negative time delays indicate situations where the probe peak precedes the peak of the pump pulse. For early times with probe ahead of the pump, oscillations are observed in the DTS spectra. For increasing overlap between pump and probe, the oscillations spread out and disappear. Similar features were observed in bulk $\mathrm{CdSe}$ and GaAs-AlGaAs-multiple-quantumwells.

In order to understand the origin of the observed oscillatory features at very early times we have developed a semiclassical theory [16]. In these theoretical studies we have assumed that the dynamical evolution of laser-excited electron-hole transitions takes place in essentially three stages. First, in the collision-free or coherent regime, different $\mathrm{k}$ states react independently to the exciting light. The light field introduces a coherent coupling between valence-band states and conduction-band states, thus driving an oscillating polarization in the matter. The semiconductor electrons exhibit Rabi-flops between the respective states in the valence band and in the conduction band not unlike the coherent electronic excitations in two-level-atom spectroscopy. No k-mixing occurs on time-scales shorter than the Coulomb scattering time. In the second stage of the band-to-band-transition dynamics, phase relaxation has occured and the electrons and holes are described by non-thermal distributions, which are locally created in k-space (spectral hole around the centre frequency of the excitation pulse). Electrons and holes are subject to the respective intraband Coulomb interaction and to the interaction

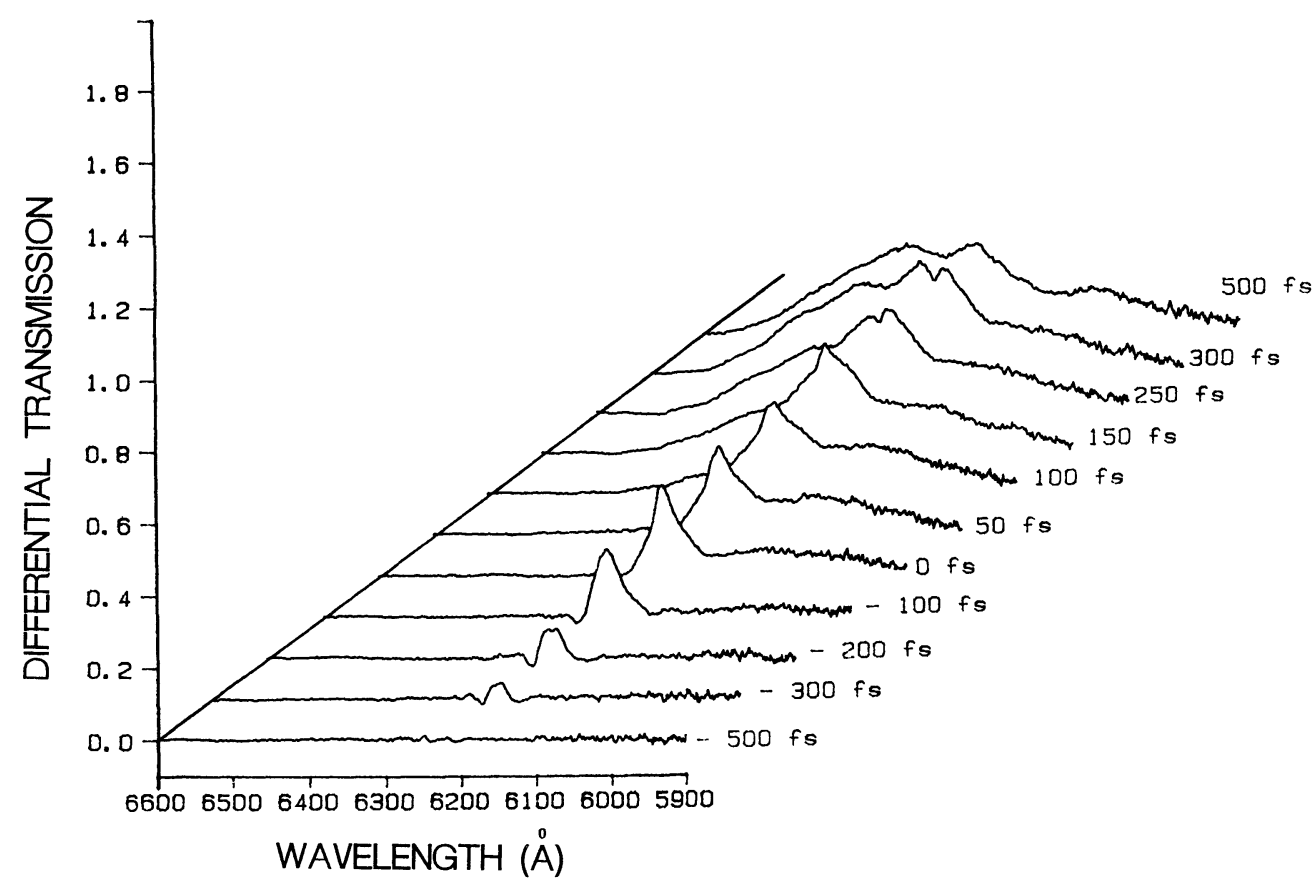

Fig. 1. - Differential transmission spectra of a $\mathrm{CdSe}_{0.2} \mathrm{~S}_{0.8}$ glass at $300 \mathrm{~K}$ at various time delays between the pump and probe pulses. 
with phonons. Both interaction mechanisms redistribute the electronic excitations towards the extrema of their respective bands. The optical excitation process acts as a local source of new electron-hole pairs. When the bands are filled up to the resonant $\mathrm{k}$-states the transition is bleached and no more light is absorbed. In the third stage, a quasi-thermal equilibrium is reached where electron-hole pairs are created by the pump beam at the same rate as they recombine radiatively or nonradiatively. For this hydrodynamic quasi-equilibrium regime it is found that the optical semiconductor spectra in the bandgap region are dominated by Coulomb and phasespace-filling effects which cause a variety of optical nonlinearities.

We argue that the oscillatory structures are a feature of the first regime where the different kstates can be treated independently. As used in the experiments, we assume a weak, short probe pulse interacting with the time-dependent medium polarization which is driven by the strong pump field. To model realistic femtosecond pulses, we assume that the amplitude of the pump has the temporal shape of a hyperbolic secant. Both probe and pump pulses are assumed to be Fourier-transform limited and coherent. The response of the semiconductors is described quantum mechanically. As is usually true in bulk semiconductors for frequencies well above the bandedge, the density of states is assumed to vary slowly with energy and bandedge effects are neglected. Transverse spatial effects are not taken into account because probe and pump pulses are orthogonally polarized.

In the case of a pump-field amplitude $E_{\mathrm{L}}$ which is small in comparison to a $\pi$-pulse, the pump-induced change of the probe absorption is found to be

$$
\begin{aligned}
\Delta \alpha(\omega)=-\alpha_{0} \operatorname{Re}[ & \int_{0}^{\infty} \mathrm{d} t \mathrm{e}^{\left(i\left(\omega-\Omega_{\mathrm{L}}\right)-\varepsilon\right) t} \times \\
& \left.\times \int_{-\infty}^{t+t_{\mathrm{p}}} \mathrm{d} t^{\prime} E_{\mathrm{L}}\left(t^{\prime}\right) E_{\mathrm{L}}^{*}\left(t^{\prime}+t\right)\right]
\end{aligned}
$$

where $\Omega_{\mathrm{L}}$, the central frequency of the pump, is well above the semiconductor bandedge, and $t_{\mathrm{p}}$ is the time difference between the maxima of the probe and pump pulses.

Examples of the computed results are shown in figure 2 for different time delays between probe and pump. The spectra show clear oscillatory structures when the probe precedes the pump. A detailed analysis [16] reveals that the frequency of the oscillations is determined by $t_{\mathrm{p}}$. When the temporal overlap between probe and pump increases, the number of oscillations and their relative amplitude decreases with respect to the central peak. The physical explanation of the observed oscillatory structures is a transient population grating coherently created with the pump and probe together. Since we

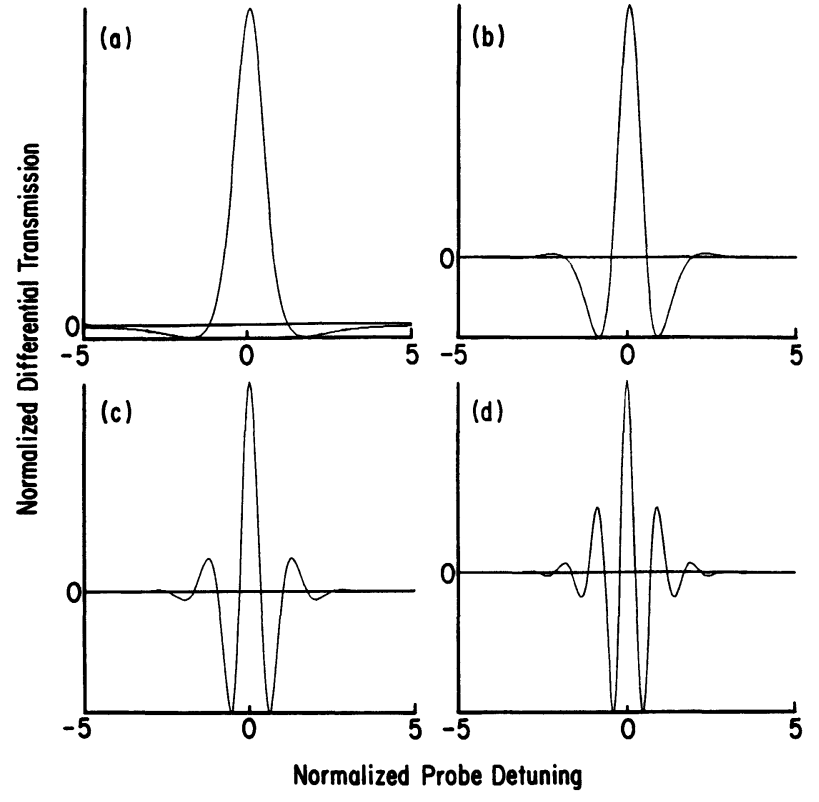

Fig. 2. - Normalized differential transmission spectra computed for different time delays $t_{\mathrm{p}}$ between pump and probe pulses : (a) $t_{\mathrm{p}}=0$, (b) $t_{\mathrm{p}}=-2 \sigma$, (c) $t_{\mathrm{p}}=-4 \sigma$, (d) $t_{\mathrm{p}}=-6 \sigma$ where $\sigma$ is proportional to the spectral width of the pump-pulse. The detuning is defined with respect to the central frequency $\Omega_{\mathrm{L}}$ of the pump-pulse spectrum : $\left(\omega-\Omega_{\mathrm{L}}\right) / \Omega_{\mathrm{L}}$.

are dealing with very short probe pulses the grating is created essentially at the time of overlap and the oscillations in the spectra are manifestations of the total effect of the interference between the probe pulse and that part of the pump pulse which is scattered from the grating in the direction of the probe beam.

Figure 3 shows a comparison between the experimental and theoretical spectra for a negative time delay between the pump and probe pulses.

As shown in figure 1, at later times after the oscillations spread out, a well-defined region of increased transmission in the vicinity of the pump position is observed. This region of increased transmission broadens and finally disappears. This phenomena is attributed to state filling effects and generation of a nonthermal carrier population (the spectral hole burning that was stated earlier). The carriers are excited in such a short time that the temperature for the distribution can not yet be defined. Subsequent carrier-carrier interactions and electron-phonon interactions redistribute the carriers and thermalization occurs in $\cong 500 \mathrm{fs}$. This phenomena has been observed previously by several groups in bulk GaAs, AlGaAs and GaAs-AlGaAs multiple-quantum-wells [17-19]. We have also seen hole burning effects in bulk CdSe similar to $\mathrm{CdSe}_{x} \mathrm{~S}_{1-x}$ microstructures in commercial glasses. (As mentioned earlier, the commercial glasses behave very much like bulk semiconductors.) The 


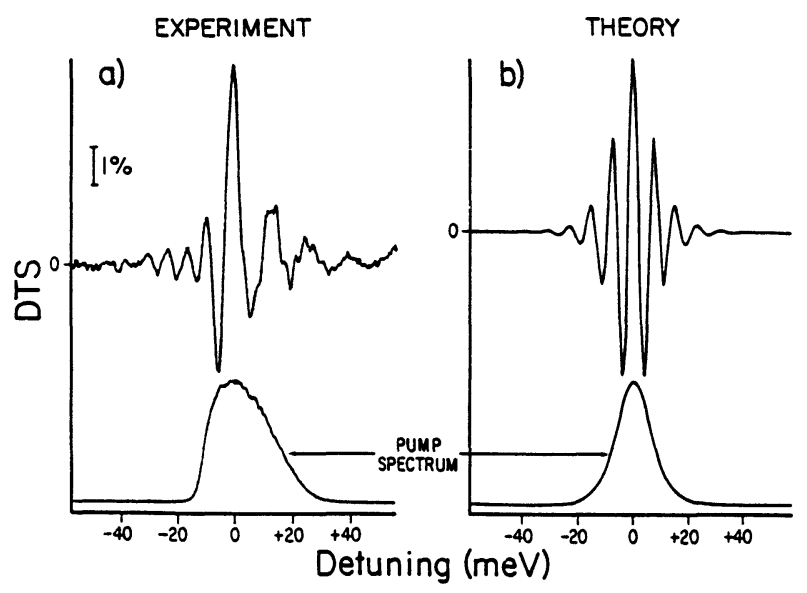

Fig. 3. - a) Experimental room-temperature differential transmission spectrum as a function of detuning from the centre of the pump-pulse spectrum for early times (pump ahead of probe) when pump and probe initially begin to overlap. b) The corresponding theoretical differential transmission spectrum. The sample consists of an 0.75$\mu \mathrm{m}$-thick CdSe single-crystal flake. The pump-pulse intensity is $2 \mathrm{GW} / \mathrm{cm}^{2}$.

spectrum labeled $500 \mathrm{fs}$ in figure 1 shows the burned hole has disappeared and the transmission spectrum has shifted to longer wavelengths. This is attributed to the bandfilling effect which results in the absorption edge to appear shifted to the higher energies.

Figure 4 shows the behaviour of the transmission spectra at later times at $T=300 \mathrm{~K}$. The $1 \mathrm{ps}$ spectrum exhibits the blue shift of the transmission spectrum, clearly demonstrating the bandfilling effect. After $1 \mathrm{ps}$ the blue shift starts to recover, indicating the onset of the carrier recombination. The carrier recombination lifetime is measured from the recovery of the blue shift of the absorption. This recovery is almost complete in 20 ps. However, a small residual shift stays for times in excess of 500 ps (which is the limit of our femtosecond delay line). We attributed this residual shift to carriers confined to traps. It has to be emphasized that the carrier lifetime in glasses is intensity dependent $:$ it is slow at small incident fluences and becomes rapid at higher fluences [8].

In conclusion, we have performed detailed experimental and theoretical studies on the ultra-fast

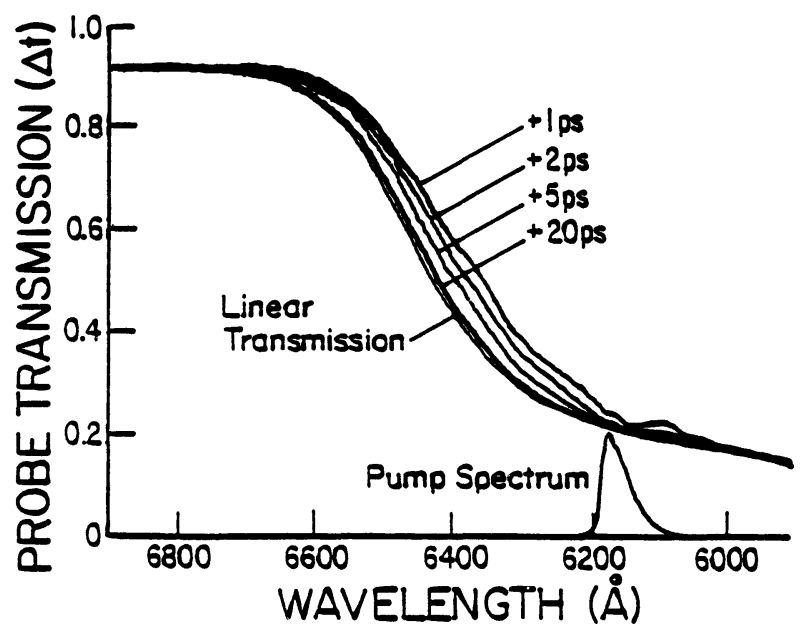

Fig. 4. - Probe transmission for $T=300 \mathrm{~K}$ and pump intensity of $0.5 \mathrm{GW} / \mathrm{cm}^{2}$ at various time delays with respect to the pump pulse for a $250 \mu \mathrm{m}$ thick $\mathrm{CdSe}_{0.2} \mathrm{~S}_{0.8}$ color glass.

dynamics of band-to-band transitions in direct-gap semiconductors. We have observed the full scenarium of coherent light-matter interaction, development of a non-coherent non-thermal distribution of the excited electrons and holes, the approach to a hydrodynamic quasi-equilibrium regime, and finally we have determined the recovery time of the absorptive changes. More detailed studies of the different time regimes are in progress for the described systems and also for materials showing excitonic features and quantum confinement effects.

This research has been performed in collaboration with M. Lindberg, G. R. Olbright and B. Fluegel. We would like to thank the U.S. Air Force Office of Scientific Research, the U.S. Army Research Office (grant \# JSOP F49620-85-C-0039), the National Science Foundation (grant \# 8610170), NATO (travel grant \# 86/0749), ONR/SDIO (grant \# N00014-86K-0719), DARPA/RADC (grant \# F30602-87-C0009), the John von Neumann Computer Center for CPU time and the Optical Circuitry Cooperative of the University of Arizona for support of this project. The authors very much appreciate scientific discussions with D. Hall and F. Borrelli of Corning Glass Works, S. W. Koch is also with the Department of Physics, University of Arizona.
[1] Jain, R. K. and Lind, R. C., J. Opt. Soc. Am. 73 (1983) 647.

[2] Yao, S. S., Karaguleff, C., Gabel, A., FortenBery, R., Seaton, C. T. and Stegeman, G., Appl. Phys. Lett. 46 (1985) 801.
[3] Roussignol, P., Ricard, D., Rustagi, K. C. and FlytZANIS, C., Opt. Commun. 55 (1985) 1431.

[4] Ekimov, A. I., Efros, A. L. and Onushchenko, A. A., Solid State Commun. 56 (1985) 921.

[5] Brus, L. E., J. Chem. Phys. 80 (1984) 4403. 
[6] Peyghambarian, N., Olbright, G. R., Кoch, S. W. and Fluegel, B., Proceedings of the NSF Workshop on Optical Nonlinearities, Fast Phenomena and Signal Processing, Ed N. Peyghambarian (Tucson, AZ) May 22-23, 1986.

[7] Nuss, M. C., Zinth, W. and Kaiser, W., Appl. Phys. Lett. 49 (1987) 1717.

[8] CotTER, D., Digest of the International Quantum Electronics Conference (Optical Society of America, Washington, D.C., 1986), postdeadline paper PD19.

[9] Olbright, G. R. and Peyghambarian, N., Appl. Phys. Lett. 48 (1986) 1184.

[10] Olbright, G. R., Peyghambarian, N., Fluegel, B. and КоCH, S. W., Opt. Lett. 12 (1987) 413.

[11] Peyghambarian, N., Opt. News, 12 (1986) 14.

[12] Borrelli, N. F., Hall, D. W., Holland, H. J. and SMITH, D. W., to be published in J. Appl. Phys. (1987).

[13] Ekimov, A. I., Efros, A. L., Onushchenko, A. A., Solid State Commun. 56 (1985) 921.
[14] Olbright, G. R., Peyghambarian, N., Fluegel, B. and Косн, S. W., Ultrafast Phenomena $V$, Eds R. Fleming and A. E. Siegman (SpringerVerlag, Berlin) 1986.

[15] Shum, K., Tang, G. C., Junnarkar, M. R. and Alfano, R. R., this volume of SPIE proceedings.

[16] Lindberg, M. and Кoch, S. W., J. Opt. Soc. Am. $B$, to be published January 1988 .

[17] Oudar, J. L., Migus, A., Hulin, D., Grillon, G., Etchepare, J. and Antonetti, A., Phys. Rev. Lett. 55 (1985) 2074.

[18] KNox, W. H., ForCK, R. L., DOWner, M. C., Miller, D. A. B., Chemla, D. S., Shank, C. V., Gossard, A. A. and Wiegmann, W., Phys. Rev. Lett. 56 (1986) 1191.

[19] Lin, W. Z., Schoenlin, R. W., Brorson, S. D., FuJimoto, J. G. and IPPEN, E., paper TUJJ2, IQEC '87 (Optical Society of America, April 1987, Baltimore, Maryland). 